\title{
Social skills and Resilience in Adolescent of Secondary Level of a public Educational Institution in Puente Piedra Lima - 2020
}

Niurka Jacome-Olacua ${ }^{1}$, Joselyne Rodríguez-Paucar ${ }^{1}$, Prhitty Marin-Garcia ${ }^{1}$, Brian Meneses-Claudio ${ }^{2, *}$, Hernan Solis-Matta ${ }^{1}$, Eduardo Matta-Solis ${ }^{3}$

${ }^{1}$ Faculty of Health Sciences, Universidad de Ciencias y Humanidades, 15314, Lima-Perú

${ }^{2}$ Image Processing Research Laboratory (INTI-Lab), Universidad de Ciencias y Humanidades, 15314, Lima-Perú

${ }^{3}$ Health Sciences, Instituto Peruano de Salud Familiar, 15304, Lima-Perú

A R T I C L E I N F O

Article history:

Received: 03 August, 2020

Accepted: 28 September, 2020

Online: 20 October, 2020

Keywords:

Social skills

Resilience

Teenagers

Relationship with the opposite sex

Spirituality

\begin{abstract}
A B S T R A C T
Social skills and resilience are very important aspects for mental health; therefore, it is necessary to take into account the positive contribution in the development of adolescents, they are in a vulnerable stage, adapting to physical, mental, emotional, etc. changes. Adolescents, not knowing how to handle the difficulties that may arise, if they do not have the ability to face it and show their positive qualities, can easily fall into depression, student desertion, early pregnancy, addictions to toxic substances (alcohol, tobacco and drugs). That is why in this study to measure social skills, the Elena Gismero Scale of Social Skills questionnaire data collection instrument was used, it has 33 items, 28 refer to the lack of assertion or social skills deficit, 5 of them refers to a positive sense. For resilience, the Connor-Davidson Resilience Scale will be used, it has 25 items. The results obtained with respect to social skills show that in the dimension positive interactions with the opposite sex shows the low level 14.3\%, which is equivalent to 45 students, they are presenting difficulties in relating to the opposite sex, regarding resilience in the dimension of spirituality, the low level of $21.7 \%$, indicates that 65 students do not have positive attitudes to fulfill their purposes. The minimum age was 11 years, the maximum age was 17 years, the mean being 13.39 in terms of sex, males predominate with a number of 154 students and 146 females.
\end{abstract}

\section{Introduction}

According to the World Health Organization and the Pan American Health Organization, they consider that in recent years adolescents from 13 to 16 years old have suffered from some mental health problem such as stress, depression or apprehension, the use of technology, cyberbullying as well as the condition that adolescents live, whether in areas where violence is used [1].

In Peru, it is estimated that there are 295 thousand people who have limitations to relate either by conduct or their way of thinking, feeling and managing their emotions, showing that $67.8 \%$ of them, which is equivalent to 200 thousand people, have moderate and severe limitations [2].

\footnotetext{
${ }^{*}$ Corresponding Author: Brian Meneses-Claudio, Mr., +51 1950159924 \& bmeneses@uch.edu.pe
}

A study carried out on the main problem adolescents face reveals that pregnancy is one of the consequences of not using contraceptive methods, due to lack of information or the myths they believe, followed by that is the state of how they live and the economic income that each family has, the physical abuse that the adolescent faces, these problems leads to the adolescent tending to suffer mental health problems such as stress, depression or apprehension, the use of technology, cyberbullying.

On the other hand, a study on depression in Peruvian adolescents was carried out in a report prepared by the Instituto Nacional de Salud Mental del Perú (INSM) with the result that 7\% of the constitutional province of Callao Lima - Peru, suffers from depression disorder, being the most frequent. In the Peruvian Amazon jungle, they reported a prevalence of $1.9 \%$, most relevant in women with $2.2 \%$ being adolescents from Lima [3]. 
A study of 352 adolescents on alcohol consumption in the city of Cajamarca revealed that $5.5 \%$ of adolescents have alcohol problems. In addition, a comparison was made in which men have a high risk of alcohol consumption with $9.5 \%$, while women have a 3.8\% high risk of alcohol consumption [5].

A study was carried out to determine the consumption of toxic and alcohol in adolescents in which $55 \%$ of its population were women between 13 and 14 years of age, $70.9 \%$ of adolescents consume alcohol. On the other hand, it was evident that $26.4 \%$ use tobacco and $14.2 \%$ cannabis. However, people who did not consume both products presented better mood and a good family relationship, therefore a good school environment [5].

However, a study was conducted to determine the relationship between resilience and self-concept with social support in a group of adolescents, resulting in a positive correlation of $26.6 \%$ in family support and support from friends, women showed a high level of self-concept with $25.4 \%$, as opposed to men who obtained $21.1 \%[6]$.

This study will show the most relevant signs that the adolescent presents in order to intervene and therefore avoid future consequences such as stress, depression, alcoholism and drug addiction. In addition, it has been identified through a bibliographic review of the National and International scientific articles that there is a lack of research in mental health in adolescents [6]. The objective of this study is to determine the relationship of social skills and resilience in adolescents of secondary level in a Public Educational Institution of Puente Piedra.

The Elena Gismero Scale of Social Skills questionnaire will be used to measure social skills, it has 33 items. The answers consist of 4 alternatives that are "I do not identify myself at all; most of the time I do not act or I would not "as well as" I very much agree and I would feel or act like this in most cases" [7]. On the other hand, the Connor-Davidson resilience instrument will be used to propose 25 items, which are distributed in 5 dimensions that are personal competence, confidence in one's own instincts, tolerance of adversity, positive acceptance of change, control and spiritual influence" [8]. The data from this research will be entered into the statistical software SPSS 24.0, since it is a correlational design study, the Pearson's Chi-square correlation test will be used for data analysis to evaluate the general objective of the study and a descriptive analysis to see the behavior of the main variables of the study.

The following research work is structured as follows: In section II, the methodology that was carried out to apply the survey collection technique will be presented. Section III will deal with the results showing the sociodemographic data of Social Skills and Resilience in adolescents, indicating the high, medium and low level according to its dimensions. In section IV, it will present the discussions of the research work. Finally, in section V, the conclusions of the research work.

\section{Methodology}

In this section, the steps for completing the questionnaire will be explained, in addition to showing the sociodemographic data.

\subsection{Research Focus and Design}

The present research is of quantitative approach, as for the methodological design, it is a cross-sectional correlational research.

\subsection{Population and Sample}

The population is made up of 300 students from the María de Los Ángeles 3070 Educational Institution which involved 154 men and 146 women, the mean age being 13.39.

\subsection{Inclusion Criteria}

- Students who are in the first to fifth year of high school in the Puente Piedra district.

- Students whose Parents have signed the informed consent to participate in the study.

- Students who agree to participate in the research study.

\subsection{Study Variable}

The present study presents two main variables that are social skills, these are a group of strategic behaviors that help developing a capacity for adolescents to contribute to solving a social situation in a way that is acceptable to both the person and the environment social, resilience is the ability that it develops people or group, to deal with difficult adversity such as trauma or a situation. Social skills and resilience in adolescents at the secondary level of a public educational institution.

\subsection{Data Collection Technique}

The technique to be used in this research work will be a questionnaire. As they are 2 variables, it presents Elena Gismero's Social Skills questionnaire consisting of 33 items, divided into 6 dimensions in which self-expression in social situations, the defense of its own rights as a consumer, the expression of anger or disagreement, being able to say no and cut interactions, make a request, and initiate positive interactions with the opposite sex. 28 of the items refer to the lack of assertion or deficit in social skills, and the remaining 5 refer to the positive sense. The responses are dichotomous for each of them, consisting of 4 response options, "I do not identify myself in absolute; most of the time it does not happen to me or it would not "as well as the positive responses" I would feel or act like this in most cases; strongly agree". In the sum of the results, it obtains high global scores, the adolescent would be expressing its social abilities and in different contexts its desertion capacity [7]. Regarding resilience, the Connor-Davidson Resilience Scale was used, it has 24 items divided into 5 dimensions that will assess personal competence, confidence in one's instincts, tolerance of adversity, positive acceptance of change and control, and spiritual influence [8].

\subsection{Procedure for Data Collection}

Arrangements will be made to the authorities to access the educational institution. First, it processed the letter of presentation of the university, the team went to the educational institution and presented ourselves to the director of the current campus. The team initiates activities such as classroom accounting. Regarding the student census, the assistant principal provided with an updated list, which allowed to identify the number of students available between 1st and 5th grade of secondary school. When identifying the number of students, coordinated with the assistant principal to carry out the surveys in an average time of one month, The time it took to do the surveys was approximately 15 to 20 
minutes per classroom, the team surveyed 4 classrooms per day, two days a week, at the time of conducting the surveys, it was quiet since the teachers collaborated so that everything is carried out correctly, as future health personnel, by applying the surveys the team has been allowed to see more closely the means of how they socialize, to know the capacities that some develop in their environment, among the needs, etc. The team also make sure that the filling and process is correct and detect in a timely manner some erroneous process that may have been presented.
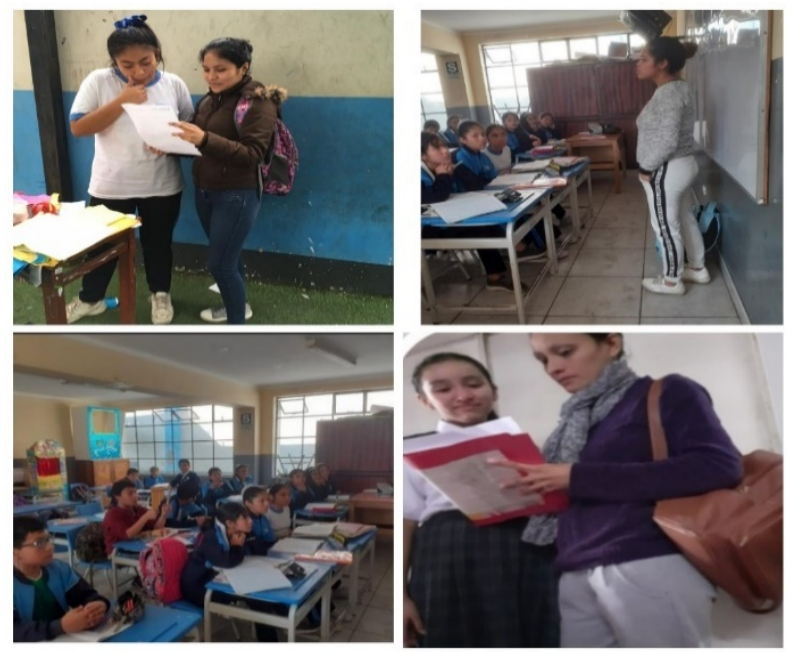

Figure 1: Carrying out the Survey on adolescents in secondary education at the María de los Ángeles Educational Institution $N^{\circ} 3070$, in the Puente Piedra district - Lima, 2019.

\section{Results}

The tables are showing the research results and the relationship between social skills and resilience.

Table 1: Sociodemographic Data on Social Kkills and Resilience in adolescents of Secondary Education of the María de Los Angeles $\mathrm{N}^{\circ} 3070$ Educational Institution, District of Puent Piedra - Lima, $2020(n=300)$

\begin{tabular}{|l|l|l|}
\hline \multirow{2}{*}{ Participant Information } & \multicolumn{2}{l}{ Total } \\
\cline { 2 - 3 } & $\mathbf{N}$ & $\mathbf{\%}$ \\
\hline Total & 300 & 100 \\
\hline Female & & \\
\hline Male & 146 & 48,7 \\
\hline Who do adolescents live with? & 154 & 51,3 \\
\hline Parents & & \\
\hline Other relatives & 191 & 63,7 \\
\hline Alone & 108 & 36,0 \\
\hline Types of Family & 1 & 0,3 \\
\hline Nuclear & & \\
\hline Extended & 184 & 61,3 \\
\hline Aggrandized & 115 & 38,3 \\
\hline Study Grade & 1 & 0,3 \\
\hline First & & \\
\hline Second & 72 & 24,0 \\
\hline
\end{tabular}

\begin{tabular}{|l|l|l|}
\hline Third & 40 & 13,3 \\
\hline Fourth & 70 & 23,3 \\
\hline Fifth & 31 & 10,3 \\
\hline
\end{tabular}

In Table 1, it has the sociodemographic data of the study participants, there were 300 adolescents from secondary education. The minimum age is 11 years old; the maximum age is 17 years old; the average is 13.39 years old.

Regarding gender, the male sex predominated with 154 students representing $51.3 \%$, followed by the female with 146 students representing $48.7 \%$.

Regarding the dimension; Who do students live with? the highest percentage was that they live with their parents with a population of 191 , which is equivalent to $63.7 \%$, followed by other relatives, 108 (36.0) and only $1(0.3)$.

The type of family nuclear families predominates with 184 (61.3\%) cases, extended family with $115(38.3 \%)$ cases and aggrandized with $1(0.3 \%)$ cases. Regarding the study grade, the distribution is heterogeneous, the students of the First grade 72 $(24.0 \%)$, the second grade $87(29.0 \%)$ and the fourth grade 70 $(23.3 \%)$ exceed in proportion to those of third grade $40(13.3 \%)$ and fifth grade $31(10.3 \%)$ of high school.

Table 2: Social Skills and Resilience in adolescents of Secondary Education of the María de Los Angeles $N^{\circ} 3070$ Educational Institution, of the Puente Piedra District - Lima, $2019(\mathrm{~N}=300)$

\begin{tabular}{|l|l|l|c|}
\hline \multicolumn{3}{|c|}{ Resilience } \\
\hline \multirow{4}{*}{$\begin{array}{l}\text { Spearman's } \\
\text { Rho }\end{array}$} & $\begin{array}{l}\text { Social } \\
\text { Skills } \\
\text { coefficient }\end{array}$ & 0,086 \\
\cline { 3 - 4 } & $\begin{array}{l}\text { Sig. } \\
\text { (Unilateral) }\end{array}$ & 0,068 \\
\cline { 3 - 4 } & $\mathbf{N}$ & 300 \\
\hline
\end{tabular}

Test correlation coefficient is $+0.086(\mathrm{p}<0.05)$. Regarding the previous results, there is no statistical evidence to confirm that there is a relationship between the variables Social Skills and Resilience.

Table 3: Social Skills in Adolescents of Secondary Education of The María De Los Angeles $N^{\circ} 3070$ Educational Institution, of the Puente Piedra District - Lima, $2019(\mathrm{~N}=300)$

\begin{tabular}{|c|c|c|c|}
\hline & & $\mathbf{N}$ & $\%$ \\
\hline \multirow{3}{*}{ Social Skills } & Low Level & 0 & 0,0 \\
\hline & Medium Level & 292 & 97,3 \\
\hline & High Level & 8 & 2,7 \\
\hline \multicolumn{2}{|l|}{ Total } & 300 & 100,0 \\
\hline
\end{tabular}

In Table 3, it can see the social skills of secondary school adolescents from the María de los Ángeles No. 3070 Educational Institution, in the Puente Piedra District - Lima where a population of 300 adolescents, 292 Students representing the 97.3 have medium level when making requests, 8 adolescents representing $2.7 \%$ have a high level when saying no and cutting 
off interactions and $0.0 \%$ do not present a low level when initiating positive interactions with the opposite sex.

Table 4: Resilience, in adolescents of Secondary Education of the María de Los Angeles $N^{\circ} 3070$ Educational Institution, of the Puente Piedra District - Lima, $2019(\mathrm{~N}=300)$

\begin{tabular}{|l|l|l|l|}
\hline \multicolumn{2}{|c|}{} & N & \% \\
\hline \multirow{3}{*}{ Resilience } & Low Level & 1 & 0,3 \\
\cline { 2 - 4 } & Medium Level & 174 & 58,0 \\
\cline { 2 - 4 } & High Level & 125 & 41,7 \\
\hline Total & 300 & 100,0 \\
\hline
\end{tabular}

In Table 4, the resilience in adolescents of secondary education of the María de los Ángeles N ${ }^{\circ} 3070$ Educational Institution of the Puente Piedra district - Lima 2019, where 174 adolescents representing $58 \%$ have a medium level of adaptation and capacity to recover, 125 adolescents representing $41.7 \%$ have a high level of control and purpose and finally 1 adolescent representing $0.3 \%$ has a low level of spirituality.

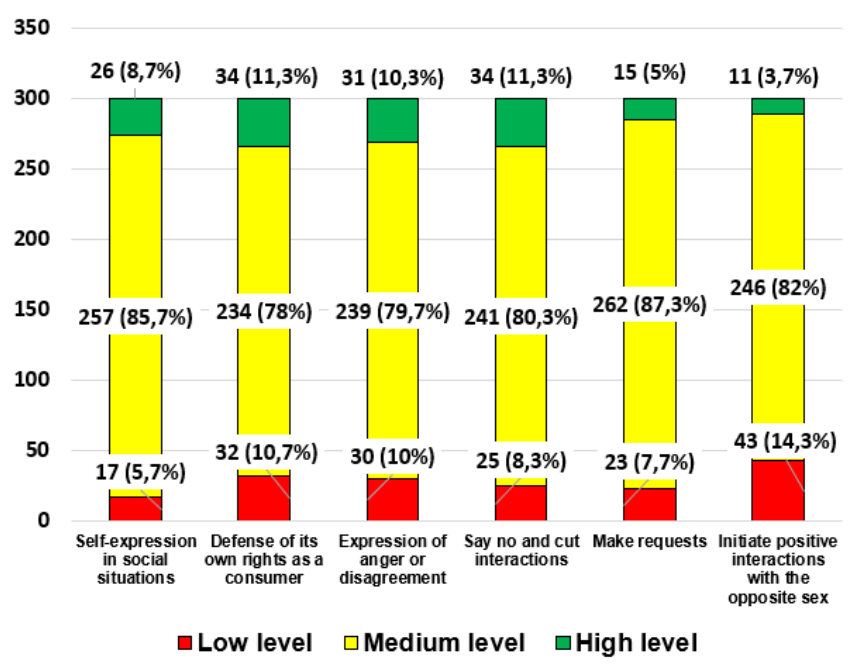

Figure 2: Social skills according to their dimensions in adolescents of Secondary Education of the María de Los Angeles $N^{\circ} 3070$ Educational Institution, of the Puente Piedra District - Lima, $2019(\mathrm{~N}=300)$

In Figure 2, it can observe social skills according to their 6 dimensions, where the most affected dimension with low level was to initiate positive interactions with the opposite sex with 43 representing $14.3 \%$ adolescents followed by the defense dimension of the its own rights as a consumer 32 that represents $10.7 \%$ of the population, the dimension of expression of anger or disagreement with 30 that represents $10 \%$, the dimension of saying no and cutting interactions with 25 which is $8.3 \%$, the dimension of making requests with 23 representing $7.7 \%$, the selfexpression dimension with 17 which is $5.7 \%$. The medium level dimension is to make requests with 262 adolescents, which is equivalent to a percentage of $87.3 \%$, the self-expression dimension with 257 represents $85.7 \%$ of the population, the dimension of initiating positive interactions with the opposite sex 246 students represent $82 \%$, the dimension saying no and cutting interactions with 241 represents $80.3 \%$, expression of anger or disagreement 239 which represents a percentage of $79.7 \%$, the dimension of defense of its own rights as a consumer with 234 which represents $78 \%$, the dimension of high level that is say no and cut interactions with 34 which represents $11.3 \%$.

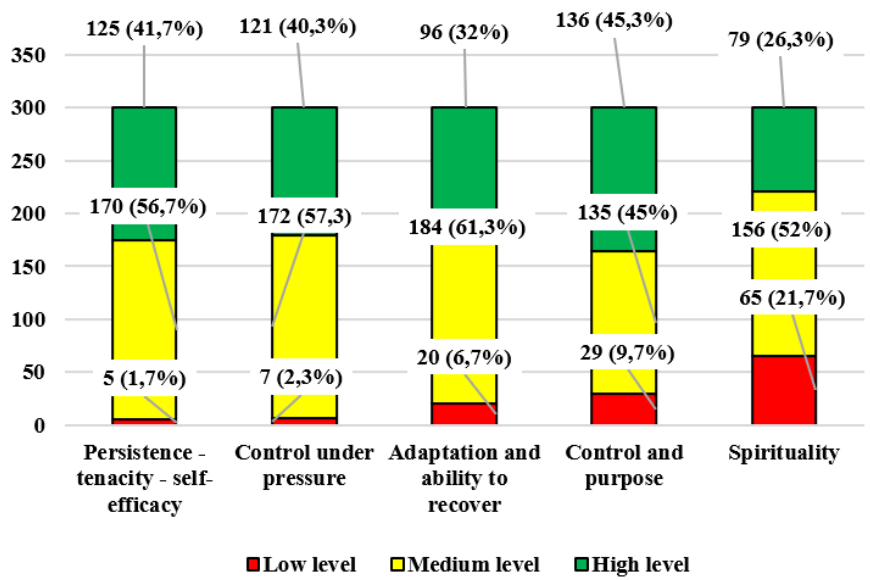

Figure 3: Resilience according to its dimensions in adolescents of Secondary Education of the María de Los Angeles $N^{\circ} 3070$ Educational Institution, of the Puente Piedra District - Lima, $2019(\mathrm{~N}=300)$

In Figure 3, it can see resilience according to its dimensions, where the most affected dimension was spirituality with 65 which represents $21.7 \%$ of adolescents, the control and purpose dimension with 29 which represents $9.7 \%$ of the population, the adaptation dimension and ability to recover with 20 which represents a percentage of $6.7 \%$, followed by the control dimension under pressure with 7 which represents a percentage of $2.3 \%$ of adolescents, the persistence-tenacity-self-efficacy dimension with 5 represents a $1.7 \%$. The medium level dimension is adaptation and ability to recover with 184 which represents $61.3 \%$, followed by the control dimension under pressure with 172 which represents $53.3 \%$ of adolescents, the persistencetenacity-self-efficacy dimension with 170 represents $56.7 \%$, spirituality with 156 which represents a percentage of $52 \%$, control and purpose with 135 represents $45 \%$. The high level dimension is control and purpose with 136 which represents a percentage of $45.3 \%$ of adolescents.

The importance of knowing the data from this study will contribute to the school authorities are going to detect any problem that may be harmful to students, such as student desertion, dependence on toxic substances such as alcohol, tobacco, drugs, depression, among others. It will also contribute to the health level in which it allows to directly identify the needs and deficits that adolescents may present, this stage is important since they can develop mentally as appropriate as possible and thus be able to focus with more attention to health Mental that is at the limit of risk in what is social skills and resilience.

\section{Discussion}

In the present research work, it shows that $58.0 \%$ of the students are at a medium level with respect to resilience, presenting higher percentages in the dimensions of spirituality, a percentage of $52.0 \%$ and in control under pressure shows the $61.3 \%$. Corroborating data on resilience in adolescence is that in the first grades there is a significant decrease in resilience, but it also shows that in intermediate grades, such as 3 rd grade, it is still low, but partially recovering in later grades. as 4 th and 5 th grades [9]. 
A study was carried out in which the effects of behavior in a social skills program in young people between 14 and 18 years of age in vulnerable situations were identified, for which two interventions were carried out, which they called pre-test and post-test, giving as result in the first one an average of $28.40 \%$ and in the post, result $86.64 \%$. This research work also obtain similar results which reinforces the risk that adolescents are in [10].

A research work was carried out in an Educational Institution regarding the well-being in adolescence in which they looked for the relationship between resilience and subjective well-being in adolescents between 12 and 15 years old, resulting in the relation between the subjective well-being and resilience in which have an average of $74.80 \%$ in their total sample, making women the most affected [11].

On the other hand, a research on the resilience implied regarding sex and educational level was carried out, it is observed that the students who participated in the research, have a high level of resilience in what is behavioral involvement, 20.29\%, which is important that make more emphasis on the emotions of adolescents in schools [12].

Compared with the reviewed studies, we reinforce that the results obtained in this study show that adolescents are at a risk level. Regarding resilience, which is worrisome since if this is not treated in time, adolescents can present difficulties to develop and easily fall into consequences such as depression, student desertion, etc. It was also evidenced that students with fewer grades represent a lower level of resilience, but that would recover progressively since in the higher grades they represent a higher level. In the following study of resilience, it indicates that women would be the most affected regarding to well-being in adolescence and resilience, even though our predominant population are men with a percentage of $51.3 \%$, it is vitally important to be aware of warning signs. Regarding to social skills, in the analyzed study, we have obtained similar results, which reinforces the importance of this study since it is necessary for the authorities to pay attention to the possible problems that the students may have, and to act as soon as possible with the support of mental health professionals and thus the quality of development of these adolescents can be improved, reinforcing their self-esteem, ability to face adversities and improve their social skills, being able to be an important contribution to society. What we want is demonstrate that at this stage of life, it is necessary to be aware because it is very easy for social problems to appear and it is also a stage where if the qualities and mental health are reinforced, these adolescents can be positively motivated resulting in good citizens.

\section{Conclusion}

Regarding Social Skills and Resilience in adolescents at the secondary level of a Public Educational Institution in Puente Piedra District, it was found that there is no significant relationship between these 2 variables.

Regarding social skills in its self-expression dimension in social situation, the medium level predominated with $85.5 \%$, followed by the high level $8.7 \%$, low level $5.7 \%$, the defense of its own rights as a consumer dimension, the medium level predominated $78 \%$, followed by the high level $11.3 \%$, low level
$10.7 \%$, in its dimension expression of anger or disagreement, the medium level predominated $79.7 \%$ followed by the high level $10.3 \%$, low level $10 \%$, in its dimension saying no and cutting interactions predominated the medium level with $80.3 \%$, followed by the high level $11.3 \%$, low level $8.3 \%$, in its dimension making requests predominated the medium level with $87.3 \%$, followed by low level $7.7 \%$ the high level with $5 \%$, in its dimension to initiate positive interactions with the opposite sex, the medium level predominated with $82 \%$, followed by the low level with $14.3 \%$, high level 3.7\%.

It can conclude that the social skills in this study indicate that 6 dimensions that the measurement scale has, 5 of them are at a medium level, followed by high level and low level. The 6th dimension must be taken into consideration, initiate positive interactions with the opposite sex, which has an medium level of $82 \%$, but followed by this is the Low level with $14.3 \%$ and the high level obtains $3.7 \%$; this would represent that students are at risk, the 6th dimension is the most worrisome since adolescents could have difficulties in relating with the opposite sex, although it is true that it considers that they are in a stage of attraction and infatuation typical of age, for this reason, it is worrying that this dimension may decrease, the authorities of this institution should have professional advice such as psychologists who can detect the reason why this interaction is decreasing, which may be an alarm sign such as low self-esteem, upbringing, family history (such as dysfunctional families, among others), leading to difficulties in developing this stage normally. Using this study, we demonstrate and emphasize that it is necessary to take mental health into account at this stage of life, since these adolescents will be the future of the country and society. Take into account how necessary is to carry out a timely control, schools or colleges and especially families add mental health as one of their priorities.

Regarding resilience in its persistence-tenacity-self-efficacy dimension, the medium level predominates with $56.7 \%$, followed by the high level with $41.7 \%$, low level $1.7 \%$; in its control dimension under pressure, the medium level predominates with $57.3 \%$, followed by the high level $40.3 \%$, low level $2.3 \%$; in its adaptation and ability to recover dimension, the medium level predominated with 184 which represents $61.3 \%$, followed by the high level $32 \%$, low level $6.7 \%$; in its control and purpose dimension, a high level predominated with $45.3 \%$, followed by a medium level $45 \%$, low level $9.7 \%$; in its spirituality dimension, a medium level predominated with $52 \%$, followed by a high level 26 , $3 \%$, low level $21.7 \%$.

It can conclude that the Resilience in the present study showed that, in the 5 dimensions of the measurement scale, they are all at a medium level, followed by the high level and finally the low level. But in the spirituality dimension, at the low level it is $21.7 \%$ which is equivalent to 65 students, this amount is very high, comparing it with the results obtained in the low levels of the other dimensions, this is worrying since that dimension refers to the conformist attitude indicator, this means that 65 students do not have positive attitudes to be able to set a goal and finish it, which is very likely that they do not want to improve their quality of life, this could be considered an alarm sign and is necessary to seek the intervention of medic professionals, psychologists among others, in order to detect the reason for this attitude, they will be able to make a more complete observation. The authorities of the institution must act as 
soon as possible so that this is improved and good mental health can be guaranteed in these adolescents, and in this way enhance their capacities to face the difficulties that arise.

\section{Conflicts of Interest}

The authors declare no conflict of interest.

\section{References}

[1]. W.H.O. Pan American Health Organization, Los jóvenes y la salud mental en un mundo en transformación, PAHO, 2018.

[2]. Ministerio de Salud, Prioridades de Investigación en Salud, Instituto Nacional de Salud, 2016.

[3]. L. Donatus, D.J. Sama, J.M. Tsoka-Gwegweni, S.N. Cumber, "Factors associated with adolescent school girl's pregnancy in kumbo east health district north west region Cameroon," Pan African Medical Journal, 31(3), 1-11, 2018, doi:10.11604/pamj.2018.31.138.16888.

[4]. J.S. Navarro-Loli, M. Moscoso, G. Calderón-De La Cruz, "Research on depression in adolescents in Peru: a systematic review," Liberabit: Peruvian $\begin{array}{llll}\text { Psychology Journal, 23(1), 57-74, } & \text { 2017, }\end{array}$ doi:10.24265/liberabit.2017.v23n1.04.

[5]. R. Leal, L. Vásquez, "INFLUENCIA DE LOS ESTILOS DE CRIANZA Y LA RESISTENCIA A LA PRESIÓN DE GRUPO SOBRE EL CONSUMO DE ALCOHOL EN ADOLESCENTES DE LA CIUDAD DE CAJAMARCA," Perspective Journal, 17(1), 33-45, 2016.

[6]. A. Rodríguez-Fernández, E. Ramos-Díaz, I. Ros, A. Fernández-Zabala, "Relaciones de la resiliencia con el autoconcepto y el Apoyo Social Percibido en una muestra de adolescentes," Psychology Action, 12(2), 1, 2015, doi:10.5944/ap.12.2.14903.

[7]. E. Gismero, EHS. Escala de Habilidades Sociales, 3rd ed., TEA Ediciones, Madrid-España, 2010, doi:10.5901/ajis.2016.v5n3s1p36.

[8]. M.I. Soler Sánchez, M. Meseguer de Pedro, M. García Izquierdo, "Propiedades psicométricas de la versión española de la escala de resiliencia de 10 ítems de Connor-Davidson (CD-RISC 10) en una muestra multiocupacional," Latin American Journal of Psychology, 48(3), 159-166, 2015, doi:10.1016/j.rlp.2015.09.002.

[9]. I. Axpe, I. Ros, E. Ramos, "Resiliencia y bienestar subjetivo en estudiantes de secundaria en funcion de variables sociopersonales," Proceedings of 3rd International Congress of Educational Sciences and Development, 26(4), 15-19, 2018.

[10]. J. Redondo-Pachecho, J.S. Parra-Moreno, M. Luzardo-Briceño, "Efectos comportamentales de un programa de habilidades sociales en jóvenes de 14 a 18 años en situación de vulnerabilidad," Pensando Psicología, 11(18), 45 58, 2015, doi:10.16925/pe.v11i18.1003.

[11]. A. Rodríguez-Fernández, E. Ramos-Díaz, I. Ros, A. Fernández-Zabala, L. Revuelta, "Bienestar subjetivo en la adolescencia: El papel de la resiliencia, El autoconcepto y el apoyo social percibido," Psychology Sum, 23(1), 6069, 2016, doi:10.1016/j.sumpsi.2016.02.002.

[12]. A. Rodríguez-Fernández, E. Ramos-Díaz, I. Ros, A. Fernández-Zabala, L. Revuelta, "Resiliencia e implicación escolar en función del sexo y del nivel educativo en educación secundaria," Open School, 44(2), 1-6, 2015, doi:10.1016/j.aula.2015.09.001. 